\title{
Polymer Nanocomposites and Cr(VI) Removal from Water
}

\author{
N.B.Singh ${ }^{1 *}$, Sarita Rai $^{2}$ and Sonal Agarwal ${ }^{1}$ \\ ${ }^{1}$ Research and Technology Development Centre, Sharda University, India \\ ${ }^{2}$ Department of Chemistry, Dr. Harisingh Gour University, India
}

Received: November 28, 2013; Accepted: January 27, 2014; Published: January 29, 2014

*Corresponding author: NB Singh, Research and Technology Development Centre, Sharda University, Knowledge Park-3, Greater Noida, 201306, India, E-mail: nbsingh43@gmail.com

\begin{abstract}
The progress in nanocomposites is varied and used in many industries. Nanocomposites can be made with a variety of enhanced physical, thermal and other unique properties. They have properties that are superior to conventional microscale composites and can be synthesized using simple and inexpensive techniques. The addition of small amounts of nanoparticles to polymers has been able to enable new properties for the composite materials. In recent years polymer nanocomposites have received significant attention because of their importance both from academic and industrial point of view. Composites, Nanocomposites in general and Polymer nanocomposites in particular have been discussed. Different type of nanocomposites and their preparations have been reviewed in brief. Application of polymer nanocomposites for the removal of $\mathrm{Cr}(\mathrm{VI})$ from aqueous solution has been described taking the examples from the literature as well as our own results. It is found that nanocomposites can be used in an effective manner for the removal of $\mathrm{Cr}(\mathrm{VI})$, a highly toxic metal ion.
\end{abstract}

Keywords: Composite; Nanocomposite; Polymer; $\mathrm{Cr}(\mathrm{VI})$

\section{Introduction}

Today's technologies require variety of materials with unusual combinations of properties which are generally not met by the conventional materials. The properties are obtained by a special class of materials known as composites. Composite materials are in general solids and obtained from the combination of two or more simple materials that develop a continuous phase and a dispersed phase. The examples of continuous and dispersed phases are polymers, metals, ceramics, etc. and glass fibers, carbon particles, silica powder, clay minerals, etc. respectively. The properties of the composites are essentially different from the components. Now the composites are being replaced by nanocomposites where nanoscale fillers are used and the materials give multifunctional properties. Even a small addition of nanoparticles has the potential to drastically transform the properties of the host polymer if it is used as a dispersed phase.

A nanocomposite is a multiphase solid material with one of the phases having dimensions less than 100 nanometers in one, two or three dimensions or structures having nanoscale repeat distances between the different phases that make up the material. During the last few years polymer nanocomposites have received significant attention because of their importance both in academia and the industry [1-5].The properties of nanocomposites depend on number of factors [6-10] such as the quality of dispersion, extent of interphase, processing methods, interfacial adhesion, loading of the particles, aspect ratio of the nanoparticles, modification of the surfaces of nanoparticles, compatibility of particle and host polymer, size of particles, and the properties of the constituents. The usefulness of nanocomposites lies in their multifunctionality which is generally not found in traditional materials.

In this article an overview of polymer nanocomposites is given in brief with special reference to their classification, preparation and applications. The removal of hexavalent chromium from water by polymer nanocomposites has been discussed.

\section{Classification of composites}

Before classifying the nanocomposites, a brief idea about the composites and their classification is essential and are given below:

Composite is a material consisting of two or more phases matrix phase and dispersed phase. Matrix is a primary phase, having a continuous character. The second phase (or phases) is embedded in the matrix in a discontinuous form and is called dispersed phase. Dispersed phase is sometimes called reinforcing phase. Types of matrices and composites are given respectively in Figures 1 \& 2.

\section{Classification of nanocomposites}

Nanocomposites are classified in number of ways. One way to classify is as:

- Inorganic filler in an inorganic matrix (inorganic inorganic nanocomposites),

- Organic filler in organic matrix (organic - organic nanocomposites),

- Hybrid materials, i.e., organic in inorganic or inorganic in organic matrix.

Based on the nanomaterial's dimensional morphology, 
nanocomposites have 1-D, 2-D, and 3-D structures.

The inorganic components in the nanocomposites can be three-dimensional framework such as zeolites, two-dimensional layered materials such as clays, metal oxides, metal phosphates, chalcogenides, and even one-dimensional and zero-dimensional materials [11-18]. Organic/inorganic nanocomposites are important for bio-ceramics and biomineralization in which in-situ growth and polymerization of biopolymer and inorganic matrix take place. Lamellar nanocomposites represent an extreme case of a composite in which interface interactions between the two phases are maximum. By judiciously engineering the polymerhost interactions, nanocomposites may be produced with a broad range of properties.

There are vast varieties of inorganic layered materials with well defined and ordered intralamellar space where other materials can be accommodated. This property enables them to act as matrices or hosts for polymers, yielding interesting hybrid nanocomposite materials.

There are two types of Lamellar nanocomposites, intercalated and exfoliated (Figure 3) [5]. In the intercalated polymer nanocomposites, there are alternating polymer chains with the inorganic layers in a fixed compositional ratio and have a well defined number of polymer layers in the intralamellar space. In exfoliated nano-composites the number of polymer chains between the layers is almost continuously variable and the layers stand $>100$ Å apart. The intercalated nanocomposites behave like compound because of stoichiometric polymer/layer ratio. This makes them interesting for their electronic and charge transport properties. On the other hand, exfoliated nanocomposites have superior mechanical properties.

\section{Polymer nanocomposites}

During the last few years a considerable interest developed in polymer nanocomposites. Varieties of nanoparticles can be incorporated into the polymer matrix to form polymer nanocomposites. There are two type of nanocomposites thermoplastic and thermoset nanocomposites.

3.3.1. Thermoplastic nanocomposites: These materials are divided into two broad categories-

(i) Commodity and (ii) Engineering resins. Nanomaterials filled thermoplastics have different properties than thermoplastics filled with conventional materials.

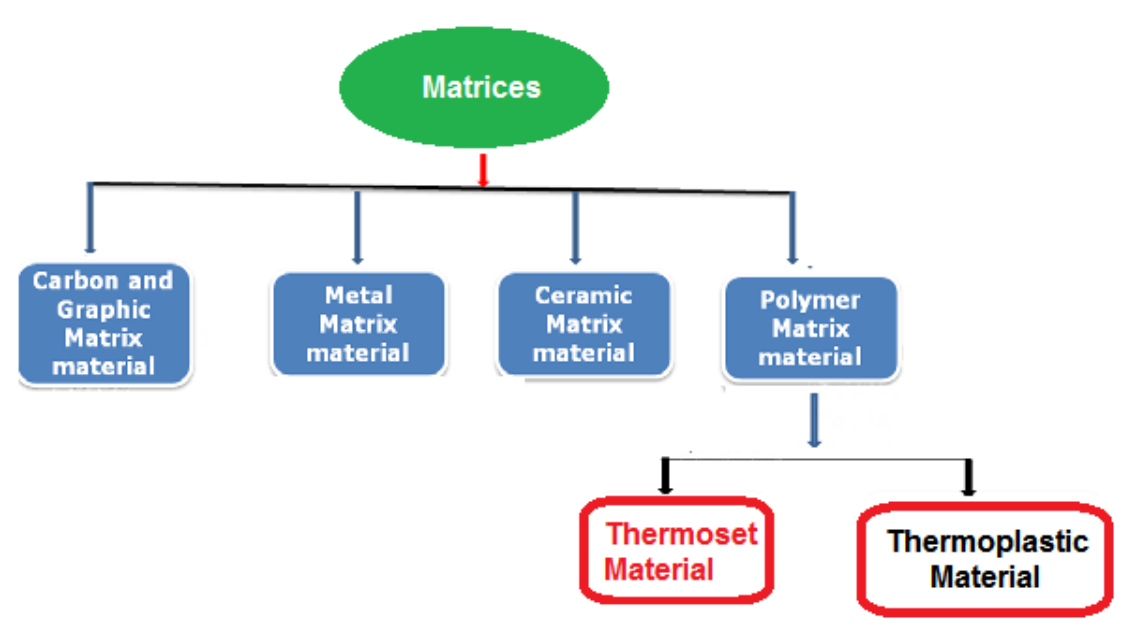

Figure 1: Classification of matrices.

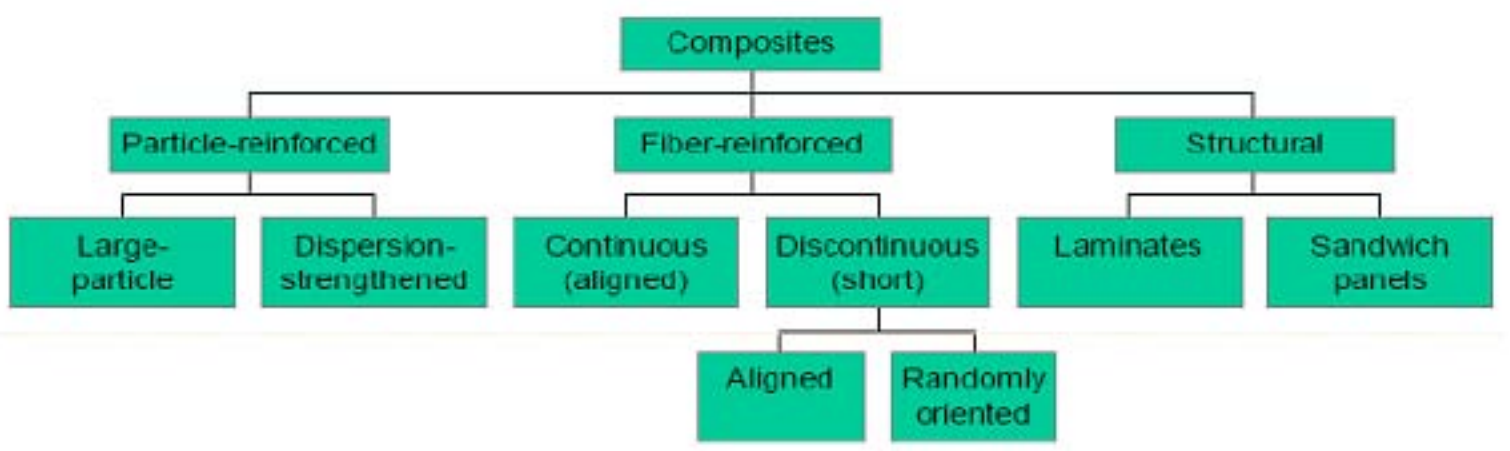

Figure 2: Type of composites. 
3.3.2. Thermoset nanocomposites: these nanocomposites are less important commercially but can be produced easily.

Following fillers may be used for the preparation of nanocomposites.

- Montmorillonite organoclays(MMT)

- $\quad$ Carbon Nanofibers (CNFs)

- $\quad$ Carbon nanotubes (CNTs)

- Metallic nanoparticles

- $\quad$ Ceramics

- $\quad$ Others

Polymer nanocomposites can also be classified based on the synthesis procedure.

1. Direct incorporation of nanomaterials into a solution or polymer melt [19].

2. In-situ generation of nanoscale building blocks in a polymer matrix (reduction of metal ions in polymer matrix) [19]. For example polyaniline/cadmium sulfide nanocomposite was prepared by dissolving polyaniline in dimethyl formamide solution and adding dimethyl cadmium. Subsequently $\mathrm{H}_{2} \mathrm{~S}$ was passed through the solution to have polyaniline/cadmium sulfide nanocomposite (Figure 4) [20].

3. Polymerization of monomers in the presence of nanoscale building blocks [19].

4. A combination of polymerization and formation of nanoscale building blocks [19].

Once the polymer is selected, basically there are two issues:

(i) Choice of nanomaterial compatible with the polymer with appropriate interfacial interaction.

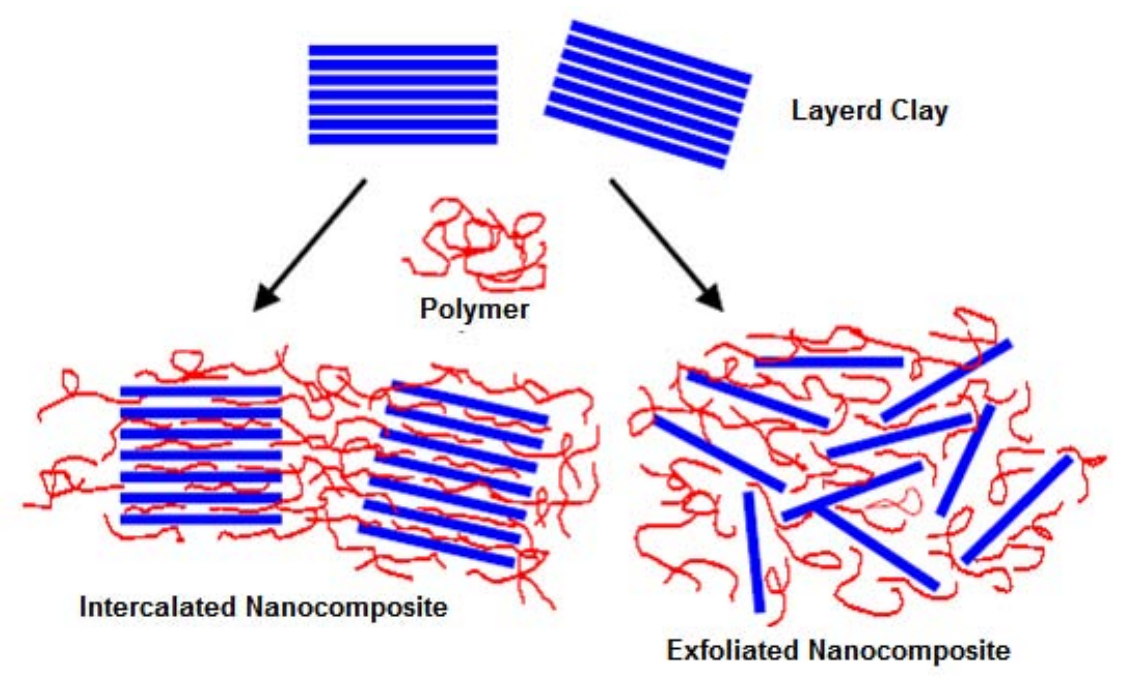

Figure 3: Intercalated and exfoliated nanocomposites.

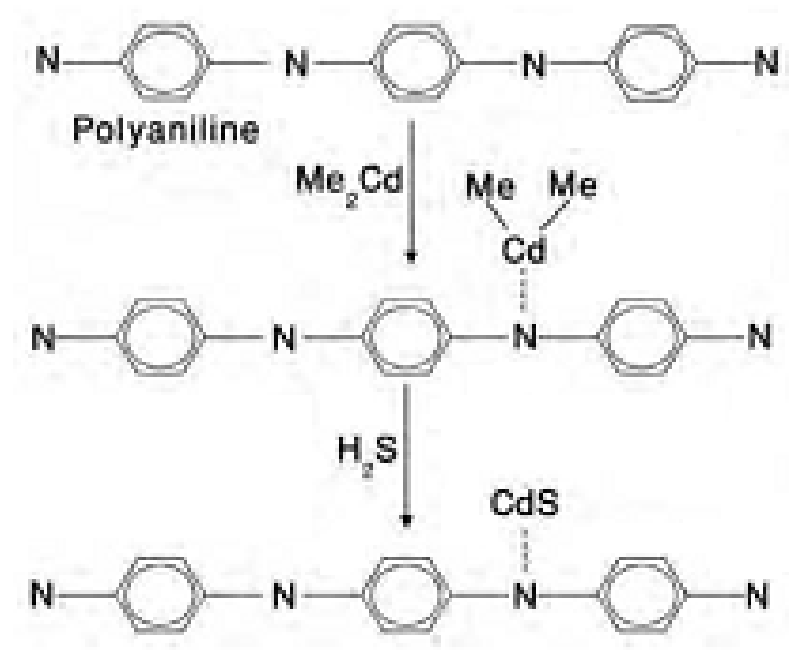

Figure 4: Polyaniline/Cadmium sulphide nanocomposite. 
(ii) Processing technique involving uniform dispersion of the nanomaterial within the polymer matrix.

\section{Preparative Methods for Polymer nanocomposites}

Polymeric nanocomposites are usually synthesized through solution route and because of this; the use of a large amount of organic solvents is required and this may pollute the environment. Therefore, effective and green synthetic methods have attracted much interest. Supercritical carbon dioxide $\left(\mathrm{scCO}_{2}\right)$ may be an alternative to the conventional processing. Generally, polymer/ inorganic filler nanocomposites can be synthesized in three different ways (Figure 5) [21]. The methods are (i) direct mixing or blending of the polymer and the inorganic fillers either as discrete phases (known as melt mixing) or in solution (solution mixing), (ii) sol-gel process which starts with a molecular precursor at ambient temperature and then forms metal oxide framework by hydrolysis and condensation and (iii) in-situ polymerization of monomers in the presence of fillers (Figure 6).

4.1. Solution processing: In his method the layerd silicates are dispersed in a suitable solvent in which the polymer is soluble. On evaporation of the solvent, the silicate sheets sandwich the polymer to form an ordered, multilayered structure (Figure 7). This process is also known as Exfoliation/adsorption process.

4.2. Melt Processing: The process has the greatest interest because of economical and flexible formulations [22]. Layered silicate is mixed with the polymer in the molten state. If layer's surfaces are compatible enough with the selected polymer, it can be inserted into the interlayer space and form the final nanocomposite (Figure 7). In this case no solvent is required.

4.3. In-situ polymerization: In this case monomers with initiators are taken and allowed to polymerize in presence of clays. The polymer chains as they grow separate the clays and enter in the interlayer space forming polymer-clay nanocomposite (Figure 8).

4.4. Formation of nanoparticles via Polymerisation: In this method nanoparticles are synthesized via polymerisation of colloidal sols containing metal ions and monomers. The particle size depends on temperature, properties of the colloidal sols, thermal coagulation and Ostwald ripening.

4.5. Sol-gel process: This includes two approacheshydrolysis of the metal alkoxides and then polycondensation

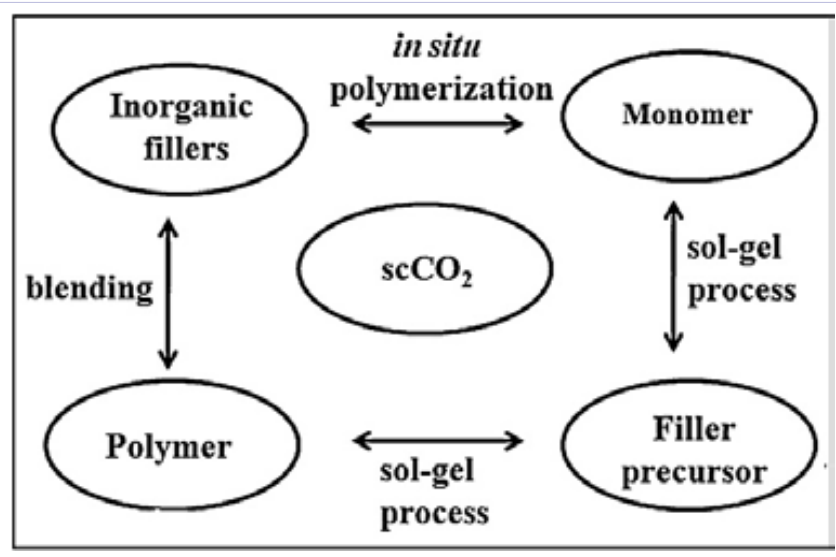

Figure 5: The three general approaches for preparation of polymer/inorganic filler nanocomposites in scCO2. Polymer-clay nanocomposites have been prepared in a number of ways as given in Figure 6.

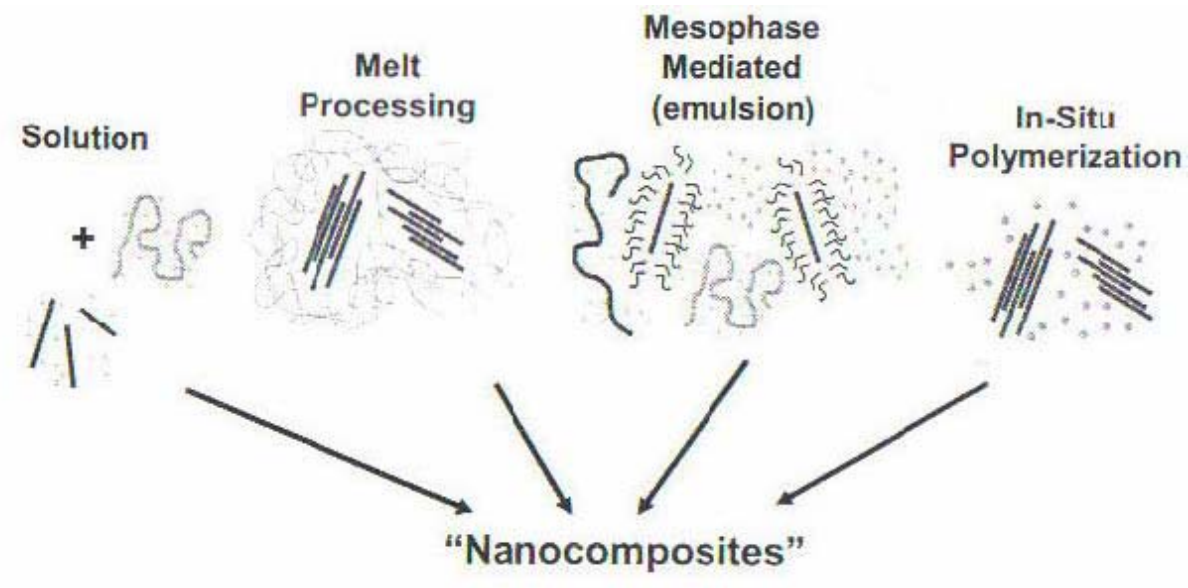

Figure 6: Synthesis of nanocomposites. 


\section{Organic treated clay}

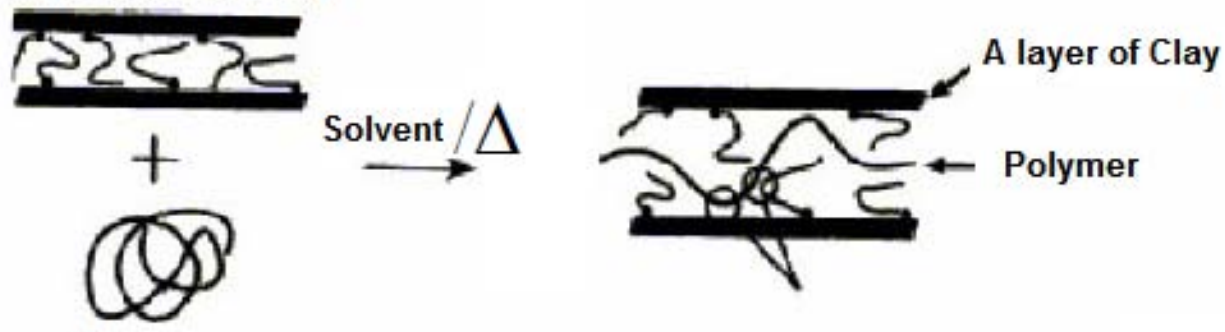

Polymer

Figure 7: Nanocomposite by solution/melt processing.

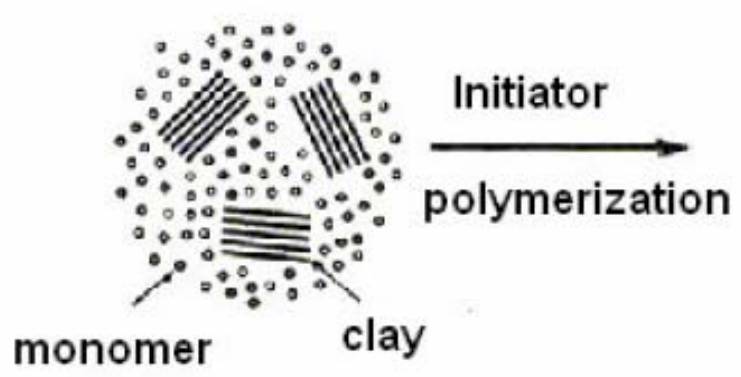

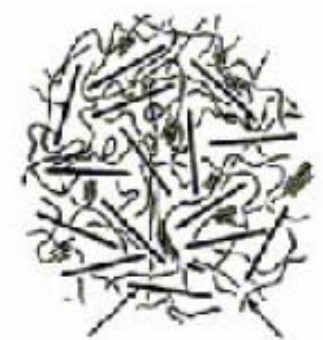

a layer polymer
of clay

Figure 8: Nanocomposite by in-situ polymerization.

\section{Starting from a masterbatch \\ Highly concentrated batch of polymer with $15-20$ wt $\%$ CNT \\ Commercially avalaible, p.e. Hyperion \\ Catalysis Intern. Cambridge, USA}

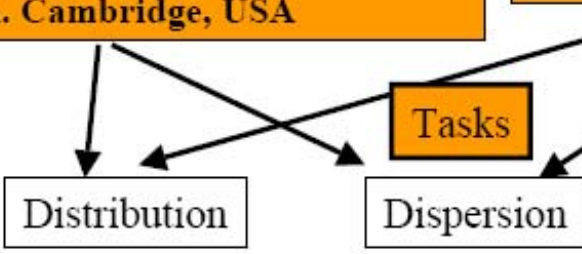

\section{Direct incorporation}

From solid premixtures of polymer powders/granules with $\mathrm{CNT}$

Safety issues have to be considered

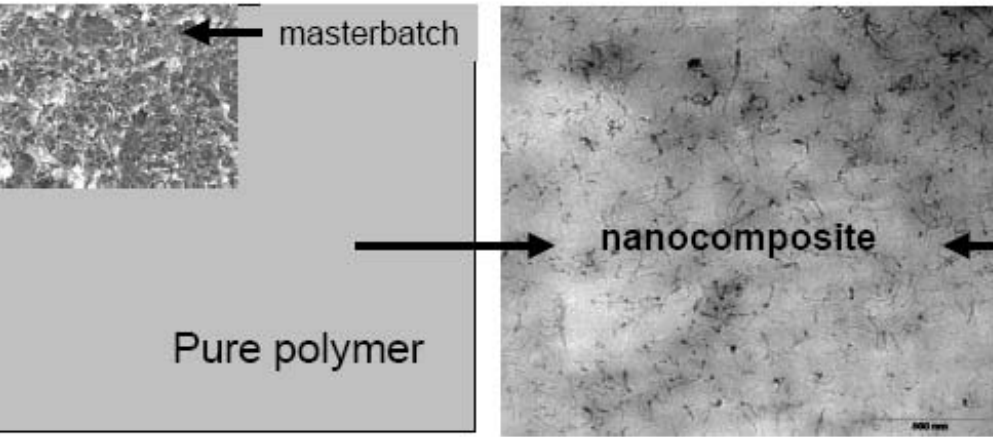

Wetting of the CNT by polymer

- Surface characteristics and interfacial tension polymer-CNT

-Melt viscosity of the polymer

Figure 9: Melt mixing of CNT with thermoplastic polymer 
of the hydrolyzed intermediates. Inorganic metal oxides can be prepared from organic metal alkoxides, halides, esters etc using this method. Transparent films of organic-inorganic hybrid materials have been made via co hydrolysis and polycondensation of alkyltrimethoxysilane-tetramethoxysilane mixtures. The solgel process using metal alkoxides is an effective way to produce inorganic-organic hybrids.

4.6. Mechanical mixing of nanoparticles with polymers: This method involves the direct mechanical mixing of a polymer solution with a pre-synthesised, highly dispersive nanoparticle solution. CdS/polyacrylamide nanocomposites have been synthesised by gamma-irradiation.

4.7. CNT-polymer nanocomposites: Due to changes in the properties there has been considerable interest in nanonocomposites of polymer and carbon nanotubes (CNT). In the preparation of CNT-polymer nanocomposite there is a

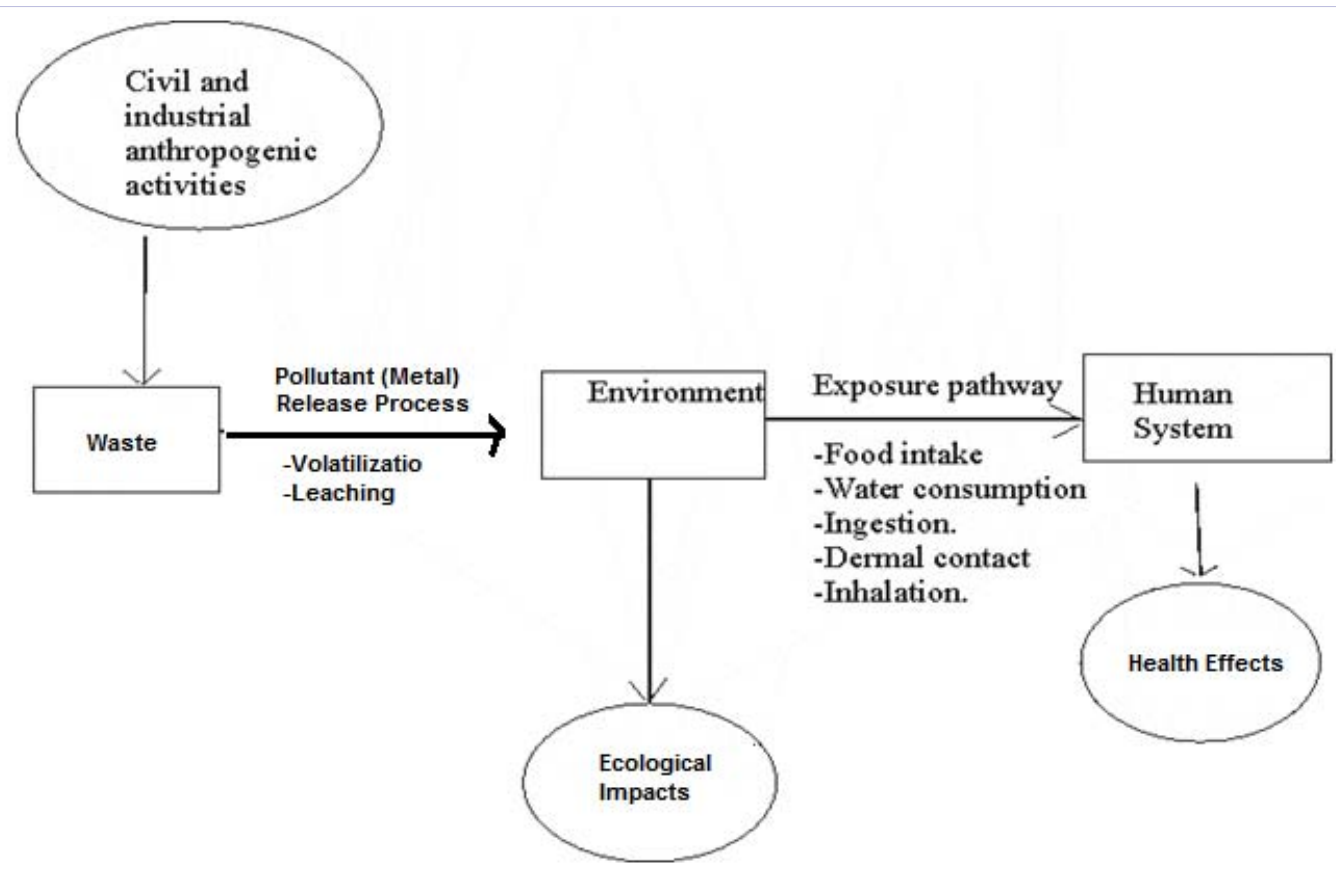

Figure 10: Relationship between metal generation, exposure pathway and environmental impact. Different sources in polluting water by heavy metals are given in Figure 11.

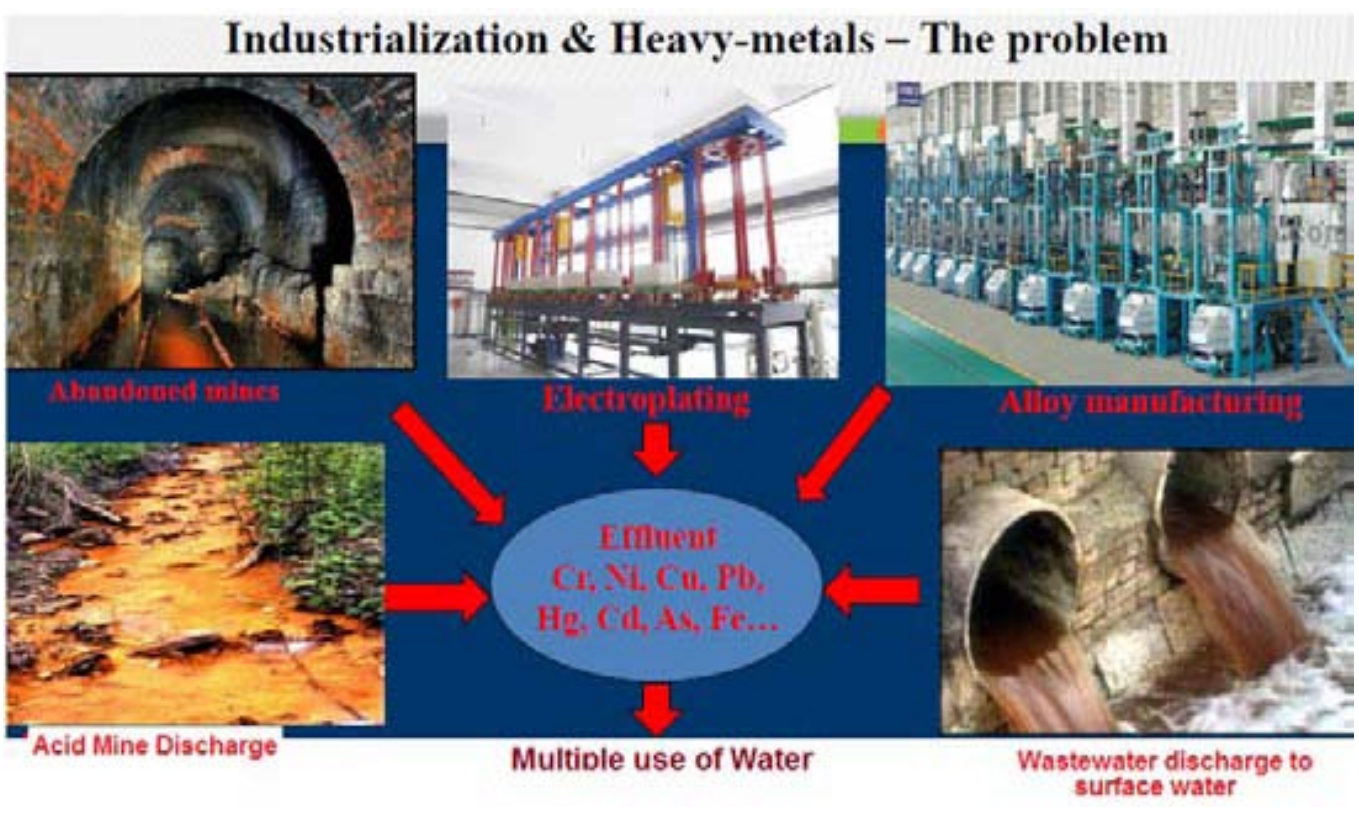

Figure 11: Different sources discharging heavy metals in water. 
problem of dispersion of CNT into polymer matrix. However the nanocomposite can be prepared by suspensions of CNT in polymer solutions and preparation of thin films or in-situ polymerization in the presence of CNT. Nanocomposite can also be prepared by melt mixing of nanotubes with polymers. Melt mixing can be done as shown in Figure 9.

\section{Water Pollution}

When toxic substances enter water bodies, they get dissolved or lie suspended or get deposited on the bed. This results in the pollution of water. Because of pollution, chemical, physical or biological changes may occur in the water. This will have a harmful effect on any living thing that drinks or uses. Polluted water diminishes the aesthetic quality of lakes and rivers, destroys aquatic life and reduces its reproductive ability. Also, it is a hazard to human health. Water pollution by heavy metal ions is considered to be one of the major environmental issues due to the adverse effects of heavy metals on ecosystem and on human health. Metal generation, exposure pathway and environmental impact are shown in Figure 10.

\section{Chromium removal from aqueous solution}

Polluted water and industrial wastewater are contaminated with chromium (III) and Cr(VI) ions. Chromium and its ions used

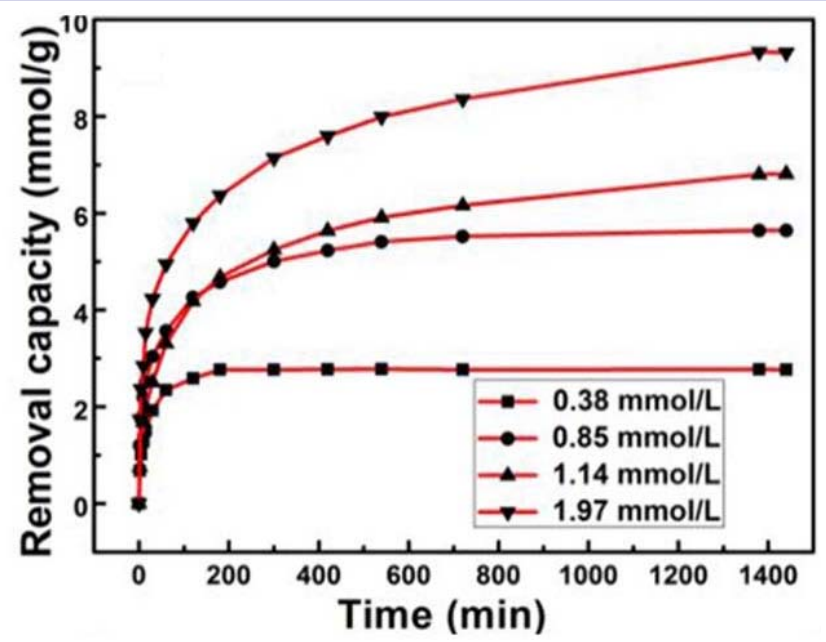

Figure 12: Effect of concentration on removal of $\mathrm{Cr}(\mathrm{VI})$ from solution by polypyrrole/graphene oxide nanosheet.

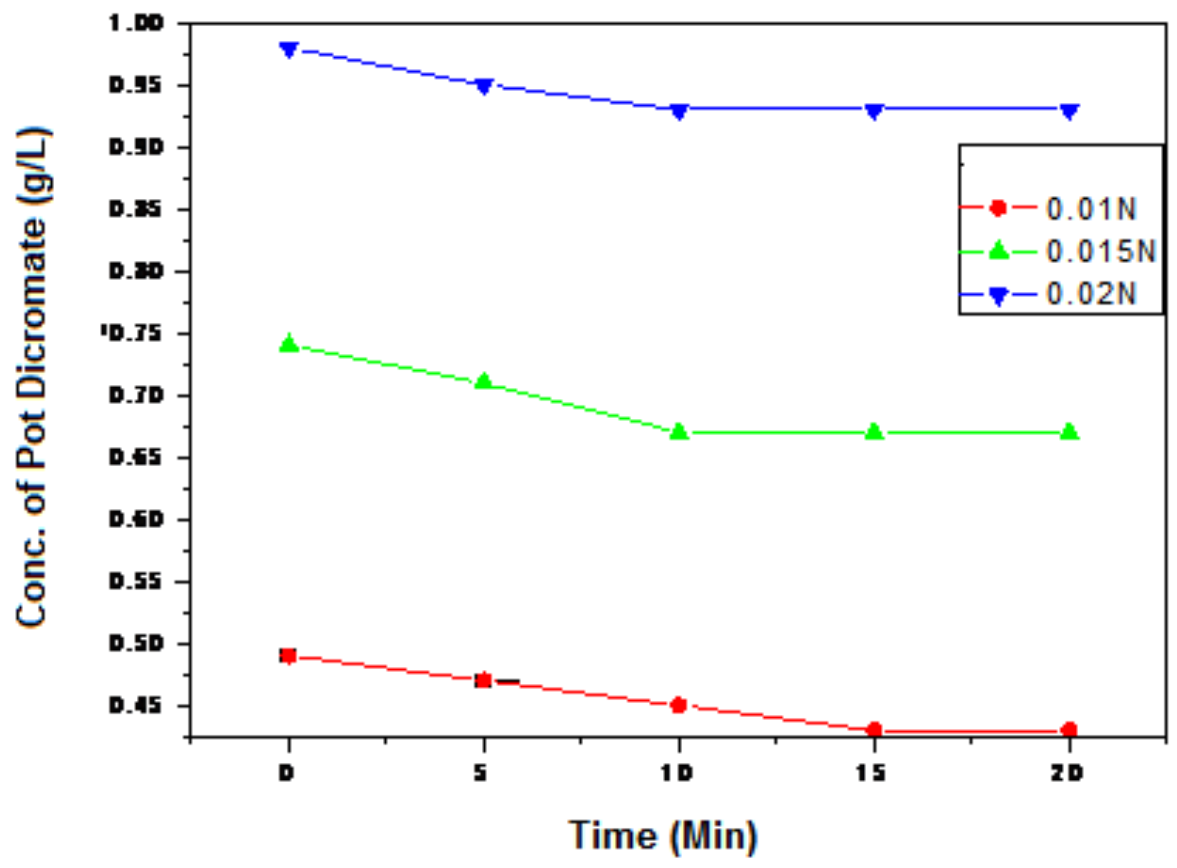

Figure 13: Removal of potassium dichromate from solution at different interval of time in the presence of ZnFe204- Polyvinyl Alcohol film. 
(a)

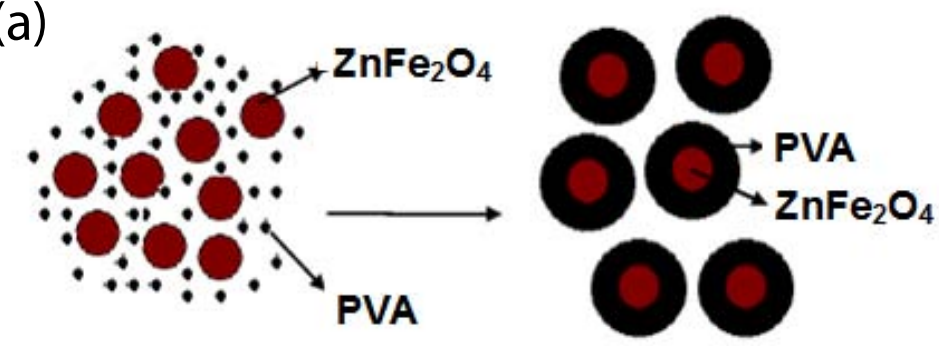

$\mathrm{PVA} / \mathrm{ZnFe} \mathrm{O}_{4}$ Nanocomposite

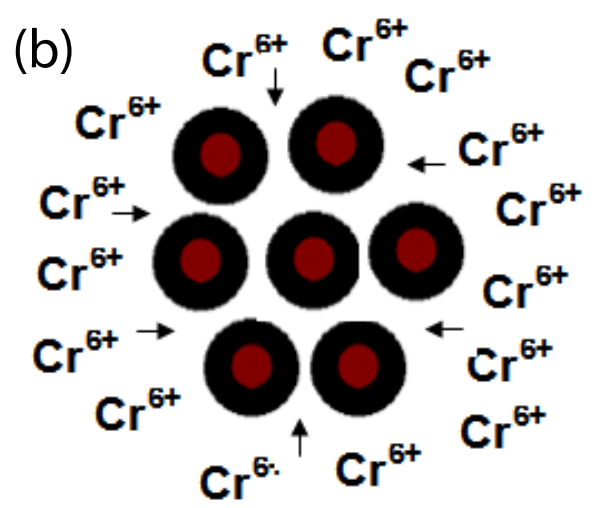

Figure 14: (a) Formation of $\mathrm{ZnFe}_{2} \mathrm{O}_{4}$-Polyvinyl Alcohol nanocomposite. (b) Adsorption of $\mathrm{Cr}^{6+}$ on the surface of $\mathrm{ZnFe}_{2} \mathrm{O}_{4}$-Poyvinyl Alcohol nanocomposite 41.

in different industries, such as: metallurgy, in steel production, anodizing of aluminum plating, dye production, textile dyeing, for metal surface cleaning processes, leather tanning, wood preservation, as a corrosion inhibitor in water-cooling towers and more (Figure 11) [23]. Hexavalent chromium (Cr(VI)) is extremely toxic and harmful whereas $\mathrm{Cr}$ (III) is relatively nontoxic. Long time interaction with $\mathrm{Cr}(\mathrm{VI})$ can cause many diseases, such as respiratory disease, nose bleeds, chronic headaches, reproductive failure, live failure, bone or organ deterioration and any type of cancer [24]. Therefore, it is necessary to remove $\mathrm{Cr}(\mathrm{VI})$ from wastewater before it is discharged to the natural water bodies. Various treatment technologies such as ion exchange, electrolytic removal, membrane filtration, reverse osmosis, chemical precipitation, adsorption, and solvent extraction have been reported for the removal of $\mathrm{Cr}(\mathrm{VI})$ from waste water [25-38]. Most of these technologies are associated with high operational and maintenance cost.

However, adsorption is found to be the most promising method particularly at low concentrations [39]. Many types of adsorbents have been used for the removal of $\mathrm{Cr}(\mathrm{VI})$. Some nanostructured adsorbents have been found to have excellent ability for removal of $\mathrm{Cr}(\mathrm{VI})$. Two defects have seriously restricted their practical applications. First, nanostructured adsorbents, especially nanoparticles, are very easy to aggregate, depriving them of their unique and excellent properties. Second, the high surface energy and the small size of nano range make them very difficult to be separated from the liquid phase after use, which restricts their recyclable applications. The best way is to use the nanoparticles in the form of nanocomposites. In this context, recent advances in nanotechnology have explored the use of nanocomposites with unique properties as adsorbents for $\mathrm{Cr}(\mathrm{VI})$. As adsorption is a surface phenomenon, nano adsorbents offer high sorption efficiency and rapid process kinetics due to their large surface area and easily accessible sorption sites [25]. A number of nanocomposites have been reported as efficient sorbents for $\mathrm{Cr}(\mathrm{VI})$ removal from aqueous solution. It is reported that polypyrrole $/ \mathrm{Fe}_{3} \mathrm{O}_{4}$ nanocomposite is a very good adsorbent for the removal of $\mathrm{Cr}(\mathrm{VI})$ from wastewater [25]. Adsorption is found to be time dependent and increases with temperature and concentration. The effect of the $\mathrm{Cr}(\mathrm{VI})$ initial concentration on the $\mathrm{Cr}$ (VI) removal by the Polypyrrole/Graphene Oxide composite nanosheets (Figure 12) has been studied [40]. Adsorption is found to be time dependent and the efficiency is higher at lower concentration.

The removal of chromium from aqueous solution of potassium dichromate of different concentrations in the presence of $\mathrm{ZnFe}_{2} \mathrm{O}_{4}$-Polyvinyl Alcohol nanocomposite film was carried out [41]. The film was kept in solution of different concentrations of $\mathrm{K}_{2} \mathrm{Cr}_{2} \mathrm{O}_{7}$. Change in dichromate concentration was determined at different time intervals and plotted in Figure 13. It is seen that the concentration of dichromate decreased with time and became constant within 15 minutes. It appears that dichromate ions are adsorbed at the surface of zinc ferrite-Polyvinyl alcohol nanocomposite and the process is time dependent. When the 
surface is covered with large number of dichromate ions, the efficiency of adsorption is reduced.

The formation of $\mathrm{ZnFe}_{2} \mathrm{O}_{4}$ - Polyvinyl Alcohol nanocomposite and adsorption of $\mathrm{Cr}^{6+}$ on the surface of nanocomposite is shown in Figure 14.

\section{Conclusion}

Discharge of metal containing effluents into water has been a cause of major concern. It is reported that water pollution causes harmful effects and particularly heavy metals in water are much more harmful to health. Traditional treatment methods are proving to be ineffective and expensive. $\mathrm{Cr}(\mathrm{VI})$ present in water even in smaller amounts is hazardous for health. Polymer nanocomposites can be very efficient and economical for removal of $\mathrm{Cr}(\mathrm{VI})$ from water solution.

\section{References}

1. Ajayan PM, Schadler LS, Braun PV (2003) Nanocomposite science and technology, WILEY-VCH Verlag GmbH Co. KGaA, Weinheim, Germany.

2. Yuan MQ, Misra RDK (2006) Polymer nanocomposites: current understanding and issues. Materials Science and Technology 22(7): 742-755.

3. Ray SS, Okamoto M (2003) Polymer/layered silicate nanocomposites: a review from preparation to processing. Progress in Polymer Science 28(11): 1539-1641.

4. Okada A, Kawasumi M, Usuki A, Kojima Y, Kurauchi T, et al. (1990) Synthesis and properties of nylon-6/clay hybrids. In Schaefer DW \& Mark JE (eds.), Polymer based molecular composites. MRS Symposium Proceedings, Pittsburgh, USA, p. 45-50.

5. Mittal V (2009) Polymer layered silicate nanocomposites: a review. Materials 2(3): 992-1057.

6. Schadler LS, Kumar SK, Benicewicz BC, Lewis SL, Harton SE (2007) Designed interfaces in polymer nanocomposites: a fundamental viewpoint. MRS Bull 32(4): 335-340.

7. Ramanathan T, Liu H, Brinson LC (2005) Functionalized SWNT/ polymer nanocomposites for dramatic property improvement. Journal of Polymer Science Part B: Polymer Physics 43(17): 2269-2279.

8. Hussain F, Hojjati M, Okamoto M, Gorga RE (2006) Review article: polymer-matrix nanocomposites, processing, manufacturing, and application: an overview. J Compos Mater 40(17): 1511-1575.

9. Gupta S, Zhang Q, Emrick T, Balazs AC, Russell TP (2006) Entropydriven segregation of nanoparticles to cracks in multilayered composite polymer structures. Nat Mater 5: 229-233.

10. Kubacka A, Serrano C, Ferrer M, Lunsdorf H, Bielecki P, et al. (2007) High performance dual-action polymer- $\mathrm{TiO}_{2}$ nanocomposite films via melting processing. Nano Lett 7(8): 2529-2534.

11. Kanatzidis MG, Wu CG, Marcy HO, Kannewurf CR (1989) Conductive polymer bronzes. Intercalated polyaniline in $\mathrm{V}_{2} \mathrm{O}_{5}$ xerogels. J Am Chem Soc 111(11): 4139-4141.

12.Wu CG, Kanatzidis MG (1991) Layered $\mathrm{V}_{2} \mathrm{O}_{5}$ xerogels: host-guest chemistry and conductive polymers. In Nazri G, et al. (eds.), Symposium on solid state ionic. MRS Symp. Proc, USA, pp. 429-442.

13. Liu YJ, DeGroot DC, Schindler JL, Kannewurf CR, Kanatzidis MG (1993) Intercalation of water-soluble polymers in $\mathrm{V}_{2} \mathrm{O}_{5}$ xerogel. Advanced Materials 5(5): 369-372.
14. Bissessur R, Schindler JL, Kannewurf CR, Kanatzidis M (1994) Nanoscale composites formed by encapsulation of polymers in $\mathrm{MoS}_{2}$. From conjugated polymers to plastics. Detection of metal to insulator transition. Mol Cryst Liq Cryst 245(1): 249-254.

15. Bissessur R, Kanatzidis MG, Schindler JL, Kannewurf CR (1993) Encapsulation of polymers into $\mathrm{MoS}_{2}$ and metal to insulator transition in metastable $\mathrm{MoS}_{2}$. J Chem Soc Chem Commun 20: 1582-1585.

16. Liu YJ, Schindler JL, DeGroot DC, Kannewurf CR, Hirpo W, et al. (1996) Synthesis, structure and reactions of poly(ethylene-oxide) $\mathrm{V}_{2} \mathrm{O}_{5}$ intercalative nano-composites. Chem Mate 8(2): 525-534.

17.Wang L, Schindler J, Kannewurf CR, Kanatzidis MG (1997) Lamellar polymer- $\mathrm{Li}_{\mathrm{x}} \mathrm{MoO}_{3}$ nanocomposites via encapsulative precipitation. J Mater Chem 7: 1277-1283.

18. Brenner J, Marshall CL, Ellis L, Tomczyk N, Heising J, et al. (1998) Microstructural characterization of highly HDS-active $\mathrm{Co}_{6} \mathrm{~S}_{8}$-pillared molybdenum sulfides. Chem Mater 10(5): 1244-1257.

19. Friedrich K, Fakirov S, Zhang Z (2005) Polymer composites. From nano- to macro-scale. Springer.

20. Khanna PK, Lonkar SP, Subbarao VVVS, Jun KW (2004) PolyanilineCdS nanocomposite from organometallic cadmium precursor. Materials Chemistry and Physics 87(1): 49-52.

21. Haldorai Y, Shim J, Lim KT (2012) Synthesis of polymer-inorganic filler nanocomposites in supercritical $\mathrm{CO}_{2}$. The Journal of Supercritical Fluids 71: 45-63.

22. Paul DR, Robeson LM (2008) Polymer nanotechnology: Nanocomposites. Polymer 49(15): 3187-3204.

23.Zelmanov G, Semiat $\mathrm{R}$ (2011) Iron $\left(\mathrm{Fe}^{+3}\right)$ oxide/hydroxide nanoparticles-based agglomerates suspension as adsorbent for chromium $\left(\mathrm{Cr}^{+6}\right)$ removal from water and recovery. Separation and Purification Technology 80(2): 330-337.

24.Xu G, Wang J, Li C (2012) Preparation of hierarchically nanofibrous membrane and its high adaptability in hexavalent chromium removal from water. Chemical Engineering Journal 198-199, 310-317.

25. Bhaumik M, Setshedi K, Maity A, Onyango MS (2013) Chromium(VI) removal from water using fixed bed column ofpolypyrrole $/ \mathrm{Fe}_{3} \mathrm{O}_{4}$ nanocomposite Separation and Purification Technology 110: 11-19.

26. Xing Y, Chen X, Wang D (2007) Electrically regenerated ion exchange for removal and recovery of $\mathrm{Cr}(\mathrm{VI})$ from wastewater. Environ Sci Technol 41(4) 1439-1443.

27.Guell R, Antico E, Salvado V, Fontas C (2008) Efficient hollow fiber supported liquid membrane system for the removal and preconcentration of $\mathrm{Cr}(\mathrm{VI})$ at trace levels. Separation and Purification Technology 62(2): 389-393.

28. Mor S, Ravindra K, Bishnoi NR (2007) Adsorption of chromium from aqueous solution by activated alumina and activated charcoal. Bioresour Technol 98(4): 954-957.

29. Carmona MER, da Silva MAP, Leite SGF (2005) Biosorption of chromium using factorial experimental design. Process Biochemistry 40(2): 779-788.

30. Kobya M (2004) Removal of $\mathrm{Cr}(\mathrm{VI})$ from aqueous solutions by adsorption onto hazelnut shell activated carbon: kinetic and equilibrium studies. Bioresour Technol 91(3): 317-321.

31. Heidmann I, Calmano W (2008) Removal of Zn(II), Cu(II), Ni(II), $\mathrm{Ag}(\mathrm{I})$ and $\mathrm{Cr}(\mathrm{VI})$ present in aqueous solutions by aluminium electrocoagulation. J Hazard Mater 152(3): 934-941. 
32. Gao P, Chen X, Shen F, Chen G (2005) Removal of chromium(VI) from wastewater by combined electro-coagulation-electroflotation without a filter. Separation and Purification Technology 43(2): 117-123.

33. Kumar PA, Chakraborty S, Ray M (2008) Removal and recovery of chromium from wastewater using short chain polyaniline synthesized on jute fiber. Chem Eng J 141(1-3): 130-140.

34. Samani MR, Borghei SM, Olad A, Chaichi MJ (2010) Removal of chromium from aqueous solution using polyaniline--Poly ethylene glycol composite. J Hazard Mater 184(1-3): 248-254.

35. Schmuhl R, Krieg HM, Keizer K (2001) Adsorption of Cu(II) and Cr(VI) ions by chitosan: kinetics and equilibrium studies. Water SA 27(1): 1-8.

36. Gupta S, Babu BV (2006) Adsorption of chromium(VI) by a low-cost adsorbent prepared from tamarind seeds. Proceedings of International Symposium \& 59th Annual Session of IIChE in association with International Partners (CHEMCON-2006), GNFC Complex.
37. Pugazhenthi G, Sachan S, Kishore N, Kumar A (2005) Separation of chromium(VI) using modified ultrafiltration charged carbon membrane and its mathematical modeling. J Membr Sci 254(12): 229-239.

38. Hongbo Gu, Sowjanya BR, Jaishri S, Yudong H, Dongmei C, et al. (2012) Magnetic polyaniline nanocomposites toward toxic hexavalent chromium removal. RSC Advances 2: 11007-11018.

39. Wu N, Wei H, Zhang L (2012) Efficient removal of heavy metal ions with biopolymer template synthesized mesoporous titania beads of hundreds micrometers in size. Environ Sci Technol 46(1): 419-425.

40. Li S, Lu X, Xue Y, Lei J, Zheng T, et al. (2012) Fabrication of polypyrrole/ graphene Oxide nanosheets and their applications for $\mathrm{Cr}(\mathrm{VI})$ removal in aqueous solution. PLoS One 7(8): e43328.

41. Agarwal S, Singh NB Zinc ferrite-polyvinyl alcohol nanocomposite and removal of hexavalent chromium $\left(\mathrm{Cr}^{6+}\right)$ from aqueous solution (under communication). 